\title{
Stability and folding dynamics of polyglutamic acid
}

\author{
Carsten Krejtschi • Karin Hauser
}

\begin{abstract}
The thermal stability and folding dynamics of polyglutamic acid were studied by equilibrium circular dichroism (CD), Fourier-transform infrared (FTIR), and time-resolved temperature-jump infrared (IR) spectroscopy. Polyglutamic acid (PGA) forms $\alpha$-helical peptides in aqueous solution and is an ideal model system to study the helix coil transition. Melting curves were monitored with $\mathrm{CD}$ and FTIR as a function of $\mathrm{pD}$. At low pD, PGA aggregates at temperatures above $323 \mathrm{~K}$, whereas at $\mathrm{pD}>5$, unfolding and refolding are reversible. At pD 5.4, a helix coil transition occurs with a transition temperature $T_{\mathrm{m}}$ of $307 \mathrm{~K}$. At slightly higher $\mathrm{pD}$ of 6.2 , the peptide conformation is already in a coil structure and only small conformational changes occur upon heating. We determined the equilibrium constant for the reversible helix coil transition at $\mathrm{pD}$ 5.4. The dynamics of this transition was measured at single IR wavelengths after a nanosecond laser-excited temperature jump of $\Delta T \sim 10 \mathrm{~K}$. Relaxation constants decreased with increasing peptide temperature. Folding and unfolding rates as well as activation energies were extracted based on a two-state model. Our study shows how equilibrium and time-resolved infrared spectroscopic data can be combined to characterize a structural transition and to analyze folding mechanisms.
\end{abstract}

Keywords Peptide dynamics · Folding . IR spectroscopy · Temperature jump · CD spectroscopy

\section{Krejtschi}

Institute of Biophysics, Goethe University Frankfurt,

Max von Laue Str. 1, 60438 Frankfurt, Germany

\section{K. Hauser ( $(-)$}

Biophysical Chemistry, Department of Chemistry,

University of Konstanz, Universitätsstr. 10,

78464 Konstanz, Germany

e mail: Karin.Hauser@uni konstanz.de

\author{
Abbreviations \\ PGA Polyglutamic acid \\ T-jump Temperature jump \\ FTIR Fourier-transform infrared \\ CD Circular dichroism
}

\section{Introduction}

Analysis of peptide conformation and dynamics is of fundamental interest for understanding of protein folding mechanisms, as peptides might be regarded as the smallest structural units of proteins. Peptides with well-defined secondary structure are ideal model systems to study structural stability and transitions. For dynamic studies, appropriate techniques are required that induce a fast perturbation for initiation of a structural change and that simultaneously provide structural sensitivity and timeresolved detection. Kinetic data and determination of reaction rates allow conclusions to be drawn about the mechanisms of folding. So far, a variety of $\alpha$-helical peptides have been used to study dynamic aspects of a helix coil transition (Williams et al. 1996; Clarke et al. 1999; Brodi et al. 1999; Abbruzzetti et al. 2000; Huang et al. 2001; Petty and Volk 2004; Gooding et al. 2005). However, the observed folding rates are surprisingly heterogeneous. Polyglutamic acid is one example of an $\alpha$-helical polypeptide whose relaxation rates vary over many orders of magnitude, as described below. Certainly it should be noted that the observed rates may also depend on the specific measurement conditions as well as on the polyglutamic acid chain length. Clarke et al. performed stopped-flow experiments inducing a $\mathrm{pH}$ jump within $0.6 \mathrm{~ms}$, 
monitoring the spectral changes by $\mathrm{CD}$ spectroscopy (Clarke et al. 1999). A pH jump from 8.0 to 3.3 revealed bi-exponential dynamics with relaxation times of $\sim 1.5$ and $\sim 6.0 \mathrm{~ms}$. The dynamics induced by a $\mathrm{pH}$ jump from 5.5 to 3.5 and from 3.3 to 8.0 could not be detected and should therefore be faster than the instrumental dead time of $0.6 \mathrm{~ms}$. Kimura et al. induced a $\mathrm{pH}$ jump from 8.0 to 4.9 by a rapid mixing method and probed spectral changes by FTIR and CD spectroscopy (Kimura et al. 2002). The FTIR spectrum obtained $100 \mu$ s after the $\mathrm{pH}$ jump was consistent with the final state. It was concluded that polyglutamic acid establishes the final helical content within $100 \mu$ s. The CD data showed controversial results. On the one hand the folding process of the helix analyzed at $222 \mathrm{~nm}$ was completed after $150 \mu \mathrm{s}$. On the other hand the signal detected at $208 \mathrm{~nm}$, which also represents an $\alpha$-helical conformation, revealed a dynamics of $250 \pm 38 \mu \mathrm{s}$. The interpretation of these different relaxation rates was as a multistep helix formation process with at least two dynamical steps. Studies of polyglutamic acid using faster perturbations techniques have also been performed. Sano and Yasunaga induced an electric field jump, detecting the optical rotation dispersion (ORD) at different $\mathrm{pH}$ values and temperatures (Sano and Yasunaga 1980). The determined relaxation times at $\mathrm{pH} 6.6$ were $\tau=3.4 \pm 0.2 \mu \mathrm{s}$ at $288 \mathrm{~K}$ and $\tau=2.4 \pm 0.2 \mu$ s at $318 \mathrm{~K}$. They determined helix growth reaction times to be $\tau=41.2 \pm 3.4 \mathrm{~ns}$ at $288 \mathrm{~K}$ and $\tau=29.4 \pm 1.7 \mathrm{~ns}$ at $318 \mathrm{~K}$ using a helix coil transition model of Schwarz and Seelig (1968) and a nucleation parameter of Snipp et al. (1965) to analyze the helix growth process. Nolan et al. used a temperature jump of $5 \mathrm{~K}$ and followed the IR transmission signals (Nolan et al. 2005). They determined similar relaxation times at room temperature, varying between 1.8 and $0.9 \mu \mathrm{s}$ as a function of the helicity, which was adjusted by changing the sample $\mathrm{pD}$.

Although there is a multitude of studies on polyglutamic acid, the folding mechanism of this $\alpha$-helical homopolypeptide is still not completely understood. The observed relaxation times after structural perturbation range from nanoseconds to milliseconds, indicating different formation processes such as helix nucleation and propagation. The structural dynamics that is monitored depends on the perturbation technique, but also the peptide length, the temperature, and the $\mathrm{pH}$ influence the conformation and conformational transition. In this paper, we present a comprehensive spectroscopic study of polyglutamic acid to characterize its thermal transition under various $\mathrm{pD}$ conditions. We used a combination of equilibrium $\mathrm{CD}$ and FTIR measurements with laser-excited T-jump IR kinetics. Thermodynamic parameters were determined using the equilibrium measurements. We demonstrate that folding and unfolding rates for the helix coil transition can be extracted from the observed kinetic rates assuming a twostate model. This two-state model is shown to be applicable for the folding dynamics at various peptide temperatures. New temperature-dependent kinetic data are provided for the folding and unfolding process of this $\alpha$-helical peptide.

\section{Methods}

Sample preparation

Polyglutamic acid (PGA, MW 50,000 100,000) was purchased from Sigma (Taufkirchen, Germany). The solid powder was dissolved in a neutral $\mathrm{D}_{2} \mathrm{O}$ solution, and the desired $\mathrm{pD}$ was adjusted by adding $\mathrm{DCl}$ or NaOD (EurisoTop GmbH, Saarbrücken, Germany). All sample concentrations were measured as $20 \mathrm{mg} / \mathrm{ml}$. The molar weight of one polyglutamic acid residue $\left(\mathrm{C}_{5} \mathrm{H}_{6} \mathrm{NO}_{3}\right)$ is $\sim 128 \mathrm{~g} / \mathrm{mol}$ considering the release of one water molecule upon polypeptide chain formation. Thus, the peptide contains 390780 residues. The $\mathrm{pD}$ was adjusted by adding $\mathrm{DCl}$ or $\mathrm{NaOD}$ and measured with a $\mathrm{pH}$ electrode using the conversion $\mathrm{pD}=\mathrm{pH}+0.4$ (Covington 1968). $\mathrm{D}_{2} \mathrm{O}$ is commonly used as a solvent instead of $\mathrm{H}_{2} \mathrm{O}$ for infrared structural analysis of proteins and peptides, since $\mathrm{H}_{2} \mathrm{O}$ has an absorption band of the $\mathrm{OH}$ bending vibration at $1,643 \mathrm{~cm}^{-1}$ (Venyaminov and Prendergast 1997) that overlaps with the spectral region of the amide I band $\left(1,6001,700 \mathrm{~cm}^{-1}\right)$. The DO bending vibration is shifted to $1,209 \mathrm{~cm}^{-1}$ due to the isotopic mass effect and thus out of the amide I frequency region. The amide I band, mainly the $\mathrm{C}=\mathrm{O}$ stretching vibration of the polypeptide backbone, is used as a marker band for secondary structure analysis. If $\mathrm{D}_{2} \mathrm{O}$ is used as the solvent instead of $\mathrm{H}_{2} \mathrm{O}$, the amide I band is termed amide $\mathbf{I}^{\prime}$.

\section{Absorption spectra in thermal equilibrium}

CD and FTIR absorption spectra were measured as a function of temperature to characterize structural transitions under equilibrium conditions and to determine thermodynamic properties. CD spectra were recorded in the spectral range from 250 to $190 \mathrm{~nm}$ from 278 to $358 \mathrm{~K}$ in steps of $2 \mathrm{~K}$ using a JASCO J-720 spectrodichrometer (Jasco, Easton, MD, USA) whose cell was temperaturecontrolled by water flow from a Julabo F25 and ME thermostatted water bath (Julabo, Seelbach, Germany). FTIR spectra were captured from 278 to $358 \mathrm{~K}$ in steps of $2 \mathrm{~K}$ using a Bruker Equinox 55 FTIR instrument (Bruker, Ettlingen, Germany) with a $\mathrm{HgCdTe}$ detector. For each spectrum, 128 scans were averaged and Fourier-transformed with spectral resolution of $4 \mathrm{~cm}^{-1}$. The temperature was varied under control of the spectrometer software 
with a thermostatted water bath (Lauda Ecoline-E300, Königshofen, Germany) connected to the cell holder. Using a homebuilt shuttle device, the sample and reference positions were moved alternately in and out of the IR beam to measure the sample and reference spectra for each temperature successively. Determining the reference and sample spectra nearly simultaneously and purging the instrument with dry air avoids the requirement for water vapor correction. Structural changes were followed by the amide $\mathrm{I}^{\prime}$ band in the spectral range $1,6001,700 \mathrm{~cm}^{-1}$. To identify the wavelengths with the most significant absorption changes, additional difference spectra were calculated with the lowest temperature spectrum at $278 \mathrm{~K}$ as reference. Homebuilt sample cells with $\mathrm{CaF}_{2}$ windows were used for both FTIR and CD measurements. The cell path lengths and sample thickness were $10 \mu \mathrm{m}$ for the CD measurements and $100 \mu \mathrm{m}$ for the IR measurements.

Analysis of the melting curves

Thermally induced structural changes of the peptide are observable by the absorption changes in the CD and FTIR equilibrium measurements. The transition is usually characterized by melting curves showing the intensity or frequency shift of a band as a function of temperature. The melting curve and thermodynamic parameters are often analyzed by fitting the data to a function of the form (van Stokkum et al. 1995; Yadav and Ahmad 2000; Huang et al. 2001; Zscherp et al. 2003; Takano et al. 2004)

$y(T)=\left(Y_{1}+m_{1} \cdot T\right)+\left(Y_{2}+m_{2} \cdot T\right) \cdot \frac{K_{\mathrm{eq}}(T)}{1+K_{\mathrm{eq}}(T)}$,

with

$K_{\text {eq }}(T)=\exp \left(-\frac{\Delta G^{\circ}(T)}{R \cdot T}\right)$

and

$$
\begin{aligned}
\Delta G^{\circ}(T)= & \Delta H_{\mathrm{m}}+\Delta C_{\mathrm{m}} \cdot\left(T-T_{\mathrm{m}}\right) \\
& -T \cdot\left(\frac{\Delta H_{\mathrm{m}}}{T_{\mathrm{m}}}+\Delta C_{\mathrm{m}} \cdot \ln \frac{T}{T_{\mathrm{m}}}\right),
\end{aligned}
$$

where $K_{\mathrm{eq}}$ is the equilibrium constant, $\Delta G^{\circ}$ is the free energy under standard conditions, $R$ is the universal gas constant, and $T$ is the absolute temperature. $T_{\mathrm{m}}$ is the melting temperature defined as the temperature at the half transition, $\Delta H_{\mathrm{m}}$ is the enthalpy change, and $\Delta C_{\mathrm{m}}$ is the heat capacity change at $T=T_{\mathrm{m}}$. Equation 1 describes the amide intensity or frequency at a certain temperature $T$ as two linear lines representing the folded and unfolded state respectively (with slopes $m_{1}$ and $m_{2}$ and ordinate intercepts $Y_{1}$ and $Y_{2}$ ) and a sigmoidal part described by $K_{\text {eq. }}$. Equations 2 and 3 allow the determination of thermodynamic parameters from the fitted melting curve.
However, the assignment of linear lines for the folded and unfolded state is sometimes difficult, and the particular choice can lead to large variations in the evaluated $\Delta H_{\mathrm{m}}$ (Allen and Pielak 1998; John and Weeks 2000). Attempts to overcome this problem were developed using an empirical approach based on a differential denaturation curve (John and Weeks 2000). We differentiated the temperature-dependent signal $y(T)$ of Eq. 1 and evaluated the data additionally with

$$
\begin{aligned}
& \frac{\mathrm{d} y(T)}{\mathrm{d} T}=m_{1} \\
& +\frac{m_{2} \cdot\left(K_{\mathrm{eq}}(T)+K_{\mathrm{eq}}(T)^{2}\right)+\left(Y_{2}+m_{2} \cdot T\right) \cdot \frac{\mathrm{d} K_{\mathrm{eq}}(T)}{\mathrm{d} T}}{\left(1+K_{\mathrm{eq}}(T)\right)^{2}}
\end{aligned}
$$

and the temperature-dependent derivative of the equilibrium constant,

$\frac{\mathrm{d} K_{\mathrm{eq}}(T)}{\mathrm{d} T}=\frac{\Delta C}{R \cdot T} \cdot K_{\mathrm{eq}}(T)+\frac{\left(\Delta H_{\mathrm{m}}-\Delta C_{\mathrm{m}} \cdot T_{\mathrm{m}}\right)}{R \cdot T^{2}} \cdot K_{\mathrm{eq}}(T)$.

Both the signal and the derivative signal were fitted simultaneously by Eqs. 1 and 4 in a global fit procedure using IGOR Pro software (WaveMetrics, Inc., OR, USA). Evaluation of the signal was performed using the intensity at $222 \mathrm{~nm}$ in the $\mathrm{CD}$ measurements and the frequency of the amide I' maximum in the FTIR measurements.

\section{Temperature-jump experiments}

T-jump experiments were performed using a homebuilt spectrometer that was described previously (Hauser et al. 2008; Krejtschi et al. 2008). The rapid heating is induced by the fundamental of a pulsed Nd:YAG Laser at 1,064 nm (5 ns pulse length, $1 \mathrm{~J} /$ pulse, Surelite III-10; Continuum Electro-Optics, Inc., Santa Clara, USA) which is Stokesshifted to 1,909 $\mathrm{nm}$ inside a Raman-Shifter (Radiant Dyes, Germany) filled with $\mathrm{H}_{2}$ at 30 bar. The $1,909 \mathrm{~nm}$ pulse excites an overtone vibration of $\mathrm{D}_{2} \mathrm{O}$ that causes nearly instantaneous heating. By splitting the 1,909 $\mathrm{nm}$ excitation beam into two components, the sample was excited from two directions of the sample cell with counterpropagating heating pulses. This decreases temperature gradients through the sample and minimizes cavitation effects (Wray et al. 2002). Furthermore, the beams were focused beyond the sample cell to avoid high power densities on the cell surface (Ballew et al. 1996). Absorption of the pulse energy by the solvent initiates the T-jump by an increase of sample temperature of approximately $10 \mathrm{~K}$. A lead salt laser diode (Laser Components, Germany) was used as a continuous single-wavelength IR source tunable over the spectral range from 1,580 to $1,700 \mathrm{~cm}^{-1}$. Since the used laser diode is a multimode emitter, the probed wavelength 
was selected by use of a monochromator (TLS 310; Mütek, Herrsching, Germany). Time-resolved transmission signals were monitored using a photovoltaic $20-\mathrm{MHz} \mathrm{HgCdTe}$ detector (KMPV11-1-J2; Kolmar Technologies, Newbury, USA) and digitized by a transient recorder board (T3012; Imtec, Hochdorf, Germany). The sample cell is identical to that used for the FTIR measurements and connected to a temperature-controlled water bath (Lauda Ecoline E300, Königshofen, Germany) that equilibrates the sample at a defined temperature before the T-jump is induced.

Transients were detected after the laser-excited T-jump at single wavelengths in the amide $\mathrm{I}^{\prime}$ region. At least 2,000 single absorption transients were averaged to obtain a better signal-to-noise ratio. For each probed wavelength, the transients were determined for several peptide temperatures. The transients contain contributions from peptide relaxation as well as solvent cooling. We used a bi-exponential model $\left[\Delta A(t)=A_{0}+A_{1} \cdot \exp \left(-t / \tau_{1}\right)+A_{2} \cdot \exp \left(-t / \tau_{2}\right)\right]$ to decompose the two contributions, each represented by a monoexponential decay function. The cooling process of the solvent is relatively slow (milliseconds) as compared with the probed peptide dynamics (microseconds). Therefore, the absorption change induced by solvent cooling interferes only minimally with the peptide dynamics. On longer time scales ( $>1 \mathrm{~ms}$ ), the solvent dynamics becomes strongly nonexponential (Ramajo et al. 2006). Thus, the data fit was restricted to a time interval up to $200 \mu \mathrm{s}$. Data within the first $500 \mathrm{~ns}$ were affected by perturbations from the instrument's electronics and possible residual scattering light from the $\mathrm{T}$-jump excitation and were thus omitted from data analysis.

\section{Results}

Spectra in thermal equilibrium

A comparison of the temperature-dependent absorption changes between FTIR and CD spectra is shown in Fig. 1. Both techniques are able to study structural changes in peptides. In IR measurements, the amide $\mathrm{I}^{\prime}$ band in the spectral range between 1,600 and $1,700 \mathrm{~cm}^{-1}$ is a marker band for secondary structure that probes mainly the $\mathrm{C}=\mathrm{O}$ stretching vibration of the polypeptide backbone. The CD measurements probe the ultraviolet (UV) region of the electronic transitions of the peptide bond between 180 and $250 \mathrm{~nm}$ for secondary structure analysis

Comparing the FTIR and CD spectra of polyglutamic acid measured at identical temperature (e.g., $278 \mathrm{~K}$ ), pD-dependent spectral differences become obvious. Between pD 4.4 and 5.4, the absorption maximum of the amide $I^{\prime}$ band occurs at $\sim 1,639 \mathrm{~cm}^{-1}$ in the FTIR spectra. This amide $\mathrm{I}^{\prime}$ band indicates an $\alpha$-helical structure. This low amide $\mathrm{I}^{\prime}$ frequency is typical for solvated, hydrogen-bonded helices in contrast to the amide $I^{\prime}$ frequencies of shielded helices in proteins that reveal typical amide $I^{\prime}$ frequencies of $\sim 1,650 \mathrm{~cm}^{-1}$ (Byler and Susi 1986; Venyaminov and Kalnin 1990; Yoder et al. 1997; Barth and Zscherp 2002; Walsh et al. 2003). At pD 6.2 , the absorption maximum of the amide $\mathrm{I}^{\prime}$ band was shifted to $1,645 \mathrm{~cm}^{-1}$. This shift of $\sim 6 \mathrm{~cm}^{-1}$ indicates reduced helicity and a conformational change from $\alpha$-helical to random coil structure. The structural change is even more obvious in the CD spectra. At pD 4.4, 4.8, and 5.4, typical $\alpha$ helical bands with absorption minima at $\sim 210$ and $\sim 223 \mathrm{~nm}$ are determined, whereas at $\mathrm{pD}$ of 6.2 , these bands disappear and only a single minimum at $\sim 197 \mathrm{~nm}$ remains. The CD data indicate a conformational change from a lefthanded helix (PPII) to a random coil structure at this higher $\mathrm{pD}$ value (Rucker et al. 2003).

Besides the structural information reflected in the amide $\mathrm{I}^{\prime}$ band, the FTIR spectra contain additional information about the fractional ionization of the side-chains as a function of $\mathrm{pD}$. Ionized carboxyl side-chains $\mathrm{COO}^{-}$ show an absorption band at $\sim 1,565 \mathrm{~cm}^{-1}$, while the deuterated form COOD has an absorption band at $\sim 1,710 \mathrm{~cm}^{-1}$ (Chirgadze and Brazhnikov 1974; Chirgadze et al. 1976; Nolan et al. 2005). At pD 4.4, there are only traces of the ionized carboxyl band in the FTIR spectra at $\sim 1,560 \mathrm{~cm}^{-1}$, while the intensity of this band increases with increasing $\mathrm{pD}$. Conversely, at $\mathrm{pD} 4.4$ the absorption band of the deuterated COOD group at $\sim 1,710 \mathrm{~cm}^{-1}$ is observable. Its intensity decreases with increasing $\mathrm{pD}$, indicating a loss of side-chain deuteration. The extent of ionization of the carboxyl side-chains even determines the conformational state of polyglutamic acid (Lumry et al. 1964). The influence of $\mathrm{pH}$ on the peptide structure was analyzed before by various techniques (Lumry et al. 1964; Myer 1969; Brodi et al. 1999).

In this study, we probed the thermal stability of the peptide at various $\mathrm{pD}$ values, as shown in Fig. 1. At pD 4.4, the heating of polyglutamic acid causes a drastic change in the amide $\mathrm{I}^{\prime}$ band. At a distinct temperature, the intensity with its maximum of absorption at $1,640 \mathrm{~cm}^{-1}$ decreases. This obvious change in absorption appears within a small temperature range between $\sim 313$ and $\sim 328 \mathrm{~K}$, and the transition temperature $\left(T_{\mathrm{m}}\right)$ was determined to be $\sim 319 \mathrm{~K}$ at $\mathrm{pD}$ 4.4. The intensities of the band at $1,602 \mathrm{~cm}^{-1}$ and the band at $1,731 \mathrm{~cm}^{-1}$ increase significantly at the same $T_{\mathrm{m}}$. These two bands remain after sample cooling (data not shown), indicating irreversible aggregation. The CD spectra also change strongly at $T_{\mathrm{m}}$ : The typical $\alpha$-helical band shape with two negative bands at $\sim 210$ and $\sim 224 \mathrm{~nm}$ disappears, leaving only one negative band at $\sim 208 \mathrm{~nm}$.

At pD 4.8, the spectral changes are not that strong. The heating process also induces an intensity decrease of the absorption band at $1,639 \mathrm{~cm}^{-1}$, while the band intensities at $\sim 1,599$ and $\sim 1,730 \mathrm{~cm}^{-1}$ increase. However, the 
Fig. 1 FTIR and CD spectra of polyglutamic acid at various $\mathrm{pD}$ values $(4.4,4.8,5.4$, and 6.2$)$ determined in thermal equilibrium. Heating was performed from 278 (blue) to $358 \mathrm{~K}($ red $)$. Left column IR absorption spectra after solvent subtraction. Right column CD spectra
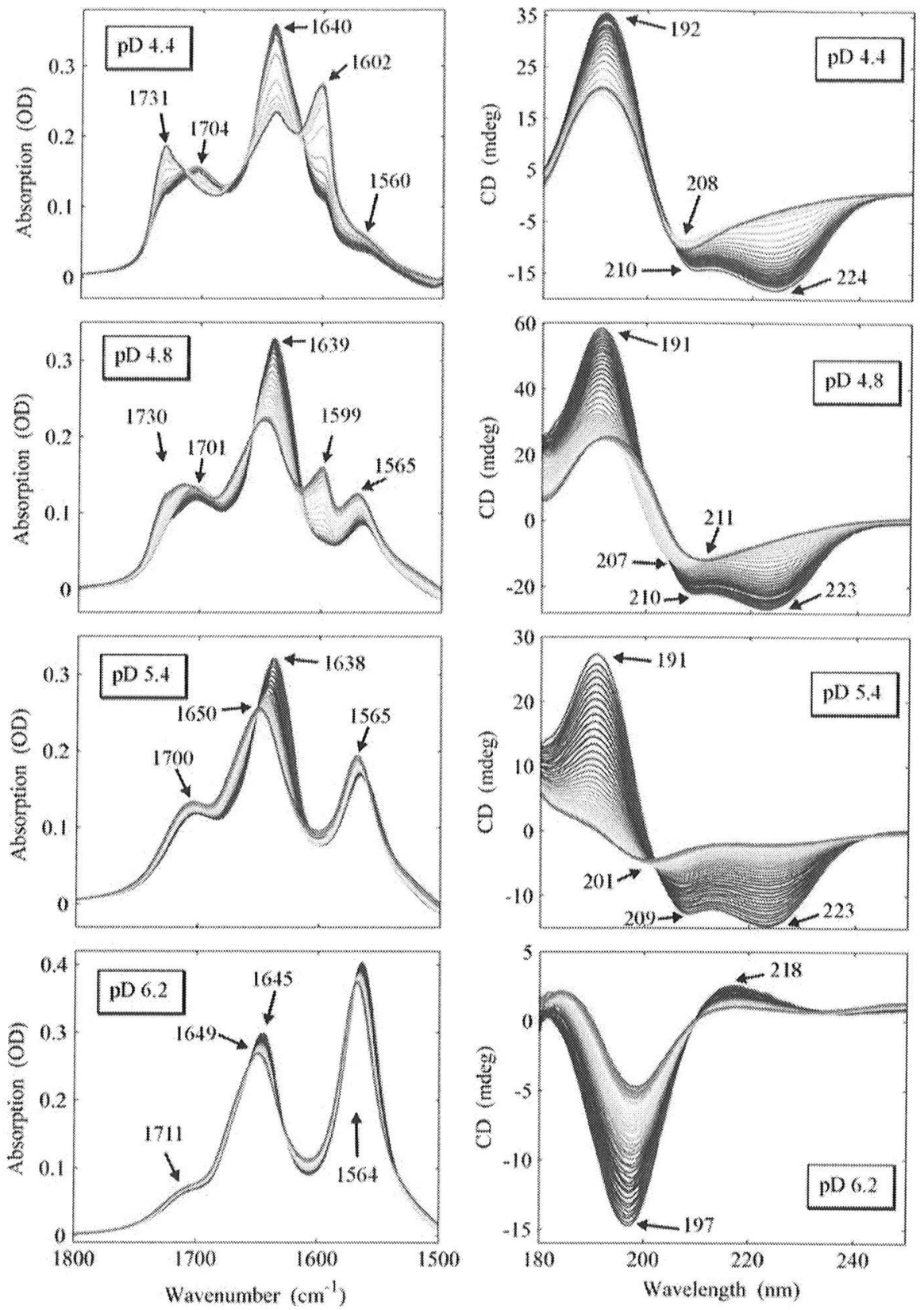

observed spectral transition is spread over a broader temperature range than that determined for $\mathrm{pD}$ 4.4. This broad transition can also be observed in the CD spectra. Similar to $\mathrm{pD} 4.4$, the spectral shape with two minima at $\sim 210$ and $\sim 223 \mathrm{~nm}$ vanishes and merges into a single negative band at $\sim 211 \mathrm{~nm}$. Before reaching the final value of the negative band at $\sim 211 \mathrm{~nm}$, the band minimum is shifted to $\sim 207 \mathrm{~nm}$. An overlap of bands possibly causes this spectral shift.

At $\mathrm{pD} 5.4$, the heating induces an intensity decrease of the absorption band at $1,638 \mathrm{~cm}^{-1}$ and a shift to
$1,650 \mathrm{~cm}^{-1}$. Further temperature-induced spectral changes are not observable. The spectral transition is expanded over a broad temperature range. In the CD spectra, a continuous decrease of the $\alpha$-helical bands is observable. The temperature-dependent band shifts and intensity variations are completely reversible at $\mathrm{pD} 5.4$.

At $\mathrm{pD} 6.2$, the temperature increase induces only marginal absorption changes. At low temperatures (278 K), the absorption maximum of the amide $\mathrm{I}^{\prime}$ band is at $1,645 \mathrm{~cm}^{-1}$. A small band shift from 1,645 to $1,649 \mathrm{~cm}^{-1}$ is noticeable over the complete temperature range of 278 to 
$358 \mathrm{~K}$. The spectra at $\mathrm{pD} 6.2$ have completely different band profiles as compared with those at lower $\mathrm{pD}$ values. An intensity decrease but no significant change of the band shape is noticeable upon heating.

As T-jump experiments require reversible folding/ unfolding conditions due to the requirement for data averaging, our kinetic studies were performed at $\mathrm{pD} 5.4$. Therefore, the equilibrium data at pD 5.4 were analyzed in more detail. The thermal transition curves contain not only information on the folding reversibility of the peptide; furthermore, the absorption signals of the data for thermal equilibrium were evaluated with Eqs. 1 and 4 to determine thermodynamic parameters. Melting curves were analyzed for FTIR and CD measurements. The temperature-induced spectral changes were probed by the frequency shift of the amide $\mathrm{I}^{\prime}$ band in the FTIR spectra and the intensity decrease at $222 \mathrm{~nm}$ in the CD spectra. Figure 2 shows the FTIR and CD signals $y(T)$ versus temperature. The model we used for the analysis of the melting curves describes the folded and unfolded state by a linear line (Eq. 1). Since the experimental data were not accessible at low temperatures, the folded $\alpha$-helical state of the peptide cannot be fitted to a linear line. As mentioned in the "Methods" section, we analyzed the melting additionally by fitting the derivatives $\mathrm{d} y(T) / \mathrm{d} T$ (Eq. 4). In our procedure, $y(T)$ and $\mathrm{d} y(T) / \mathrm{d} T$ are fitted simultaneously to the melting curves. We determined the thermodynamic parameters of the helix coil transition. The fit analysis of the FTIR and CD data provided nearly identical thermodynamic parameters. At pD 5.4, the transition temperature $\left(T_{\mathrm{m}}\right)$ was determined to be $307.2 \pm 1.5 \mathrm{~K}$ for the FTIR data and $314.5 \pm 2.8 \mathrm{~K}$ for the $\mathrm{CD}$ data. The enthalpy change at $T_{\mathrm{m}}$ is $-54.45 \pm 2.57 \mathrm{~kJ} \mathrm{~mol}^{-1}$ and $-63.12 \pm 1.65 \mathrm{~kJ} \mathrm{~mol}^{-1}$, respectively, while the determined values for the heat capacity change have large errors, but the absolute values are small and thus nearly negligible. An overview of the fitted thermodynamic parameters is given in Table 1 .

The FTIR equilibrium spectra also provide the possibility of wavelength selection for T-jump experiments. Difference spectra representation is particularly helpful to identify the most significant spectral changes upon heating. Figure 3 shows an intensity increase at $1,660 \mathrm{~cm}^{-1}$ and a decrease at $1,632 \mathrm{~cm}^{-1}$ upon heating. Wavelengths were chosen for the T-jump experiments within a spectral region of $\pm 5 \mathrm{~cm}^{-1}$ around 1,660 and $1,632 \mathrm{~cm}^{-1}$, also depending on the emission wavelength of intense lead salt laser modes. The choice of peptide temperature for the T-jump experiment is ambiguous because of the broad spectral transition (Fig. 2). Therefore, T-jump studies were performed at different peptide temperatures to study the influence of these temperatures on the relaxation dynamics.

Temperature-jump dynamics

pD 5.4 was chosen for the T-jump experiments because of the reversibility of unfolding/refolding of polyglutamic acid upon heating and cooling. Relaxation transients of polyglutamic acid are shown in Fig. 3 (right) exemplarily for one specific peptide temperature detected at the wavelengths $1,659.1$ and $1,631.8 \mathrm{~cm}^{-1}$. Within the presented time interval up to $20 \mu \mathrm{s}$, the observed kinetic traces can be separated into two distinct phases: a slow and a fast one. During the fast phase, energy of the excitation radiation at $\sim 1,909 \mathrm{~nm}$ is absorbed and excites an overtone vibration of the solvent. This energy of the heating pulse is absorbed and dissipated by the solvent within the exposed
Fig. 2 Melting curves of polyglutamic acid at $\mathrm{pD} 5.4$ obtained by monitoring the frequency shift of the amide $\mathrm{I}^{\prime}$ maximum with FTIR (squares) or the intensity at $222 \mathrm{~nm}$ with $\mathrm{CD}$ (filled circles) as a function of temperature. Left temperature dependent signals. Right derivatives of the temperature dependent signals. Fits were derived according to Eqs. 1 and 4
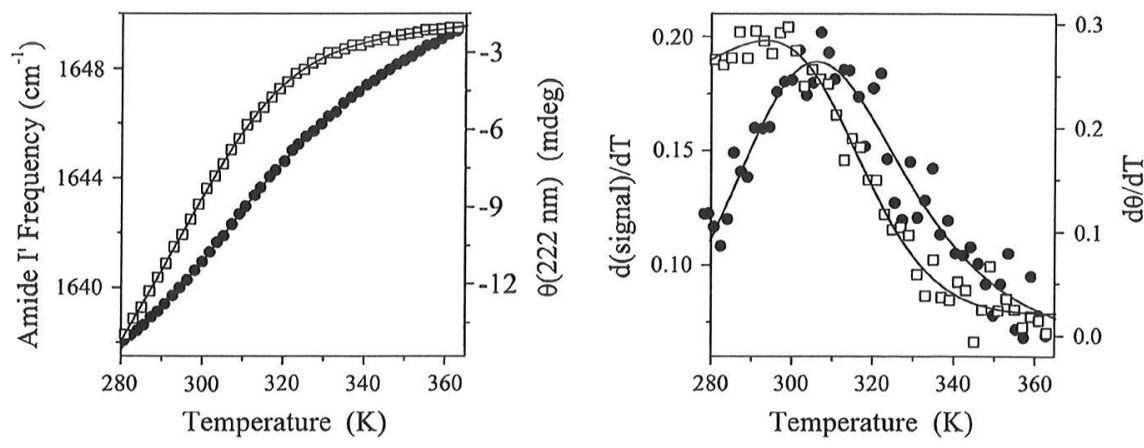

Table 1 Thermodynamic parameters derived from the melting curves probed in thermal equilibrium

\begin{tabular}{llccr}
\hline & Technique & $\Delta H_{\mathrm{m}}\left(\mathrm{kJ} \mathrm{mol}^{-1}\right)$ & $\Delta C_{\mathrm{m}}\left(\mathrm{J} \mathrm{mol}^{-1} \mathrm{~K}^{-1}\right)$ & $T_{\mathrm{m}}(K)$ \\
\hline Amide I' frequency shift & FTIR & $54.45 \pm 2.57$ & $10.0 \pm 62.5$ & $307.2 \pm 1.5$ \\
Intensity at 222 nm & $\mathrm{CD}$ & $63.12 \pm 1.65$ & $3.8 \pm 169.5$ & $314.5 \pm 2.8$ \\
\hline
\end{tabular}




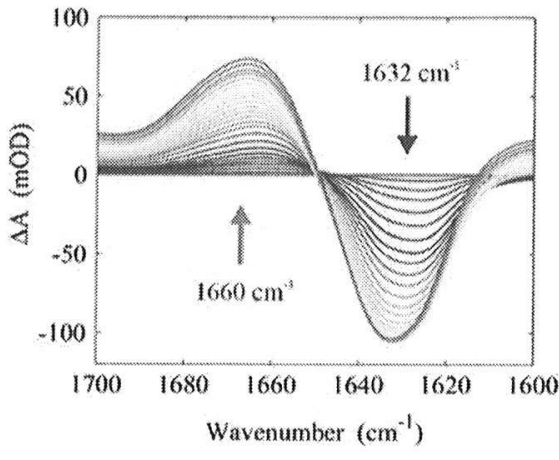

Fig. 3 Helix coil transition of polyglutamic acid monitored with equilibrium FTIR and time resolved T jump measurements at pD 5.4. Left Difference spectra with reference spectra at $278 \mathrm{~K}$; arrows

volume and is faster than our instrumental time resolution, being virtually complete within the laser pulse (Genberg et al. 1987; Anfinrud et al. 1989). Additionally, as presented in Fig. 3 (right), the fast phase of the dynamics shows wavelength-dependent magnitudes of the absorption change. Although a similar T-jump was induced, $\Delta A$ is larger at $1,631.8 \mathrm{~cm}^{-1}$ than at $1,659.1 \mathrm{~cm}^{-1}$. This is consistent with the spectral changes observed in equilibrium measurements of $\mathrm{D}_{2} \mathrm{O}$ (data not shown) where larger absorption changes are induced at $1,630 \mathrm{~cm}^{-1}$ than at $1,660 \mathrm{~cm}^{-1}$ upon similar temperature variations.

After the fast drop of absorption due to the fast kinetics of the heating process, a slower phase of the T-jump dynamics follows. Those absorption changes (Fig. 3, right) can clearly be associated to peptide relaxation. Within the time range of $\sim 500 \mathrm{~ns}$ to $20 \mu \mathrm{s}$, the transient absorption signal decreases at $1,659.1 \mathrm{~cm}^{-1}$. It becomes obvious that the fast absorption decay of the solvent within the first $\sim 500 \mathrm{~ns}$ causes a $\Delta A$ signal of $\sim 13 \mathrm{mOD}$ which decreases slowly. It reaches a stable $\Delta A$ plateau $\sim 15 \mu$ s after the laser-excited $\mathrm{T}$-jump. The heat-induced absorption changes of the solvent and of the peptide have opposite directions. This results in the small amplitude of the $\Delta A$ signal of $\sim 7 \mathrm{mOD}$ at $1,659.1 \mathrm{~cm}^{-1}$ on later time scales. This time-resolved absorption change of the peptide itself is consistent with the absorption increase detected in equilibrium measurements of polyglutamic acid at this wavelength. However, the first fast absorption drop within $\sim 500 \mathrm{~ns}(\Delta A \sim 25 \mathrm{mOD})$ in the dynamics at $1,631.8 \mathrm{~cm}^{-1}$ is followed by a further absorption decrease $(\Delta A \sim 37 \mathrm{mOD})$ within $\sim 10 \mu \mathrm{s}$. This negative absorption change is also verifiable with the data obtained in thermal equilibrium.

As shown in Fig. 4, the analysis of these relaxation dynamics was performed in a time interval of $500 \mathrm{~ns}$ to $200 \mu$ s. The slower phase of the observed T-jump dynamics can be further separated into two components:

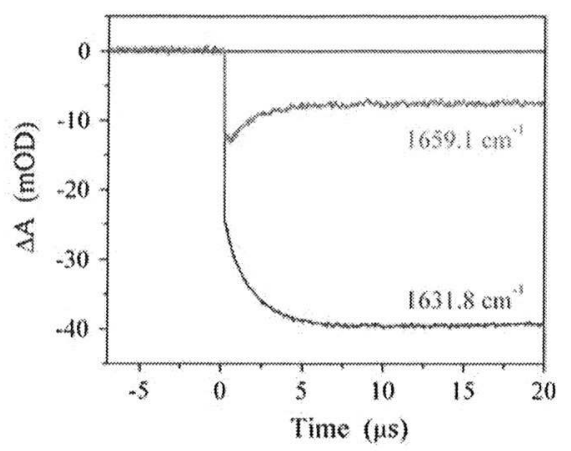

indicate the wavenumbers used for $\mathrm{T}$ jump probing. Right $\mathrm{T}$ jump transients at $1,631.8$ and $1,659 \mathrm{~cm}^{-1}$ without the separation of solvent contributions

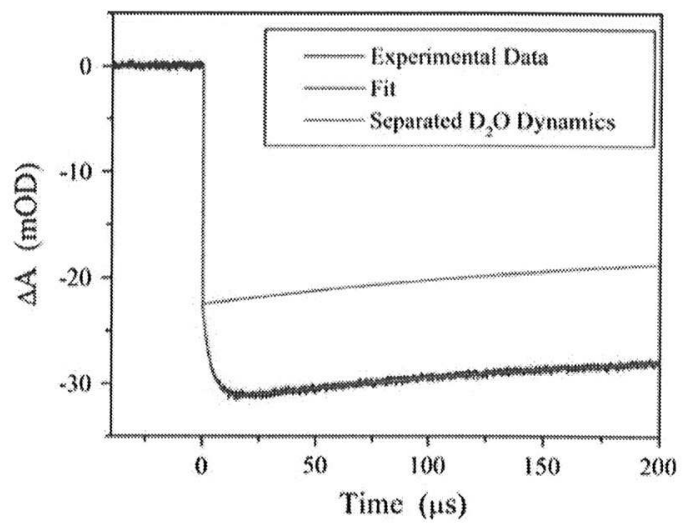

Fig. 4 Observed relaxation transients (black) at $1,631.8 \mathrm{~cm}^{-1}$ after a T jump from 276 to $286 \mathrm{~K}$ without separation of solvent contribu tions. Transients are described by a bi exponential function (red line): $\triangle A(t) \quad A_{0}+A_{1} \cdot \exp \left(t / \tau_{1}\right)+A_{2} \cdot \exp \left(t / \tau_{2}\right)$ with $A_{0} \quad 25.6 \times$ $10^{-3} \mathrm{mOD}, A_{1} \quad 9.2 \times 10^{-3} \mathrm{mOD}$, and $\tau_{1} \quad 4.0 \mu \mathrm{s}$ for PGA and $A_{2} \quad 6.1 \times 10^{-3} \mathrm{mOD}$ and $\tau_{2} \quad 213.2 \mu$ s for $\mathrm{D}_{2} \mathrm{O}$. The blue line represents the fit of the solvent contribution due to the cooling process

the kinetics of the peptide relaxation between the unfolded and folded conformation, and the solvent dynamics due to cooling. As mentioned in the "Methods" section, a bi-exponential decay can adequately describe the timeresolved absorption signals in the selected time region ( $500 \mathrm{~ns}$ to $200 \mu \mathrm{s}$ ). Thus, the transients can be decomposed into two mono-exponential components representing the slow cooling of the solvent $\left(\tau_{\mathrm{S}} \sim 213.2 \mu \mathrm{s}\right)$ as well as the faster peptide relaxation $\left(\tau_{\mathrm{P}} \sim 4.0 \mu \mathrm{s}\right)$. With an initial temperature of $276 \mathrm{~K}$ and a temperature jump to approximately $286 \mathrm{~K}$, a relaxation time of $4.0 \mu \mathrm{s}$ was determined for polyglutamic acid, whereas the solvent relaxation was $\sim 50$ times slower.

After subtraction of the water relaxation, the remaining transient consists only of the peptide dynamics. This procedure was performed for all transients probed at various 
temperatures. Results are shown exemplarily for some temperatures in Fig. 5. The temperature values refer to the temperatures at the new thermal equilibrium after the T-jump of $\sim 10 \mathrm{~K}$ was induced. While at $1,631.8 \mathrm{~cm}^{-1}$ the absorption decreases, an increase is obtained at $1,659.1 \mathrm{~cm}^{-1}$. Influences of the peptide temperature on the relaxation constants can already be noticed in the shown transients. A more quantitative validation provides the plot of the relaxation times versus the peptide temperature as shown in Fig. 6. Relaxation times decrease with increasing temperature for both probed wavelengths, at $1,631.8 \mathrm{~cm}^{-1}$ representing the decay of $\alpha$-helix and at $1,659.1 \mathrm{~cm}^{-1}$ representing the increase of coil structure. Furthermore, the plot indicates that the temperature dependences of the relaxation time match for both probed wavelengths. Comparison of the relaxation times at similar final peptide temperatures is presented in Table 2 . At a temperature of $\sim 286 \mathrm{~K}$, a relaxation time of $4.07 \pm 0.03 \mu \mathrm{s}$ at $1,631.8 \mathrm{~cm}^{-1}$ and a relaxation time of $3.87 \pm 0.11 \mu \mathrm{s}$ at $1,659.1 \mathrm{~cm}^{-1}$ were determined. For higher temperatures, e.g., at $\sim 301 \mathrm{~K}$, the relaxation times are almost identical for both probed wavelengths, being $0.70 \pm 0.01 \mu$ s for $1,631.8 \mathrm{~cm}^{-1}$ and $0.76 \pm 0.04 \mu$ s for $1,659.1 \mathrm{~cm}^{-1}$.

The similar relaxation times for the $\alpha$-helix decay and the coil rise is valid for a wide temperature range between 285 and $315 \mathrm{~K}$. Thus, the assumption of a two-state model seems to be reasonable, allowing the decomposition of the observed relaxation rates into unfolding and refolding rates. Thereby, the relaxation rate $k_{\mathrm{obs}}\left(=1 / \tau_{\mathrm{obs}}\right)$ is the sum of the folding $k_{\mathrm{f}}$ and unfolding $k_{\mathrm{u}}$ rate $\left(k_{\mathrm{obs}}=k_{\mathrm{u}}+k_{\mathrm{f}}\right)$. The ratio of the folding and the unfolding rate is given by the equilibrium constant $K_{\mathrm{eq}}(T)=k_{\mathrm{f}} / k_{\mathrm{u}}$ (Bieri and Kiefhaber 2000). The equilibrium constant can be determined from

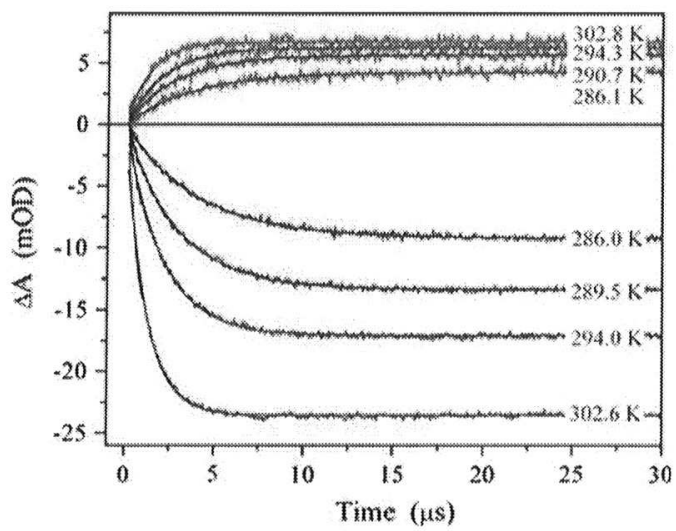

Fig. 5 Relaxation transients of polyglutamic acid at different tem peratures after separation of the solvent contributions. The decrease in $\Delta A$ at $1,631.8 \mathrm{~cm}^{-1}$ (blue) represents the $\alpha$ helix decay, whereas the increase in $\Delta A$ at $1,659.1 \mathrm{~cm}^{-1}$ (red) represents the rise of the coil structure equilibrium FTIR (Xu et al. 2003; Dyer et al. 2004) or CD (Dimitriadis et al. 2004) data, as we did by using Eqs. 1 and 4. We used the thermodynamic parameters of $\Delta H_{\mathrm{m}}=-54.45 \mathrm{~kJ} \mathrm{~mol}^{-1}, \Delta C_{\mathrm{m}}=10.0 \mathrm{~J} \mathrm{~mol}^{-1} \mathrm{~K}^{-1}$, and $T_{\mathrm{m}}=307.2 \mathrm{~K}$ derived from the FTIR data to determine the equilibrium constant $K_{\mathrm{eq}}(T)$. Using this equilibrium constant and the relaxation rates $k_{\mathrm{obs}}$ observed from the T-jump measurements, we extracted the folding $k_{\mathrm{f}}$ and unfolding $k_{\mathrm{u}}$ rates. These rates are presented in an Arrhenius plot in Fig. 7 (left). The activation energies of these rates were determined by evaluating the Arrhenius equation $\left[\ln (k)=\ln (A) \quad E_{\mathrm{a}} / R T\right]$ and are shown in Table 3. We found that the absolute value of the activation energy $E_{\mathrm{a}}$ of $50.00 \pm 0.84 \mathrm{~kJ} \mathrm{~mol}^{-1}$, which was derived from $k_{\mathrm{obs}}$, is nearly identical to the enthalpy change $\Delta H_{\mathrm{m}}$ of $-54.45 \pm 2.57 \mathrm{~kJ} \mathrm{~mol}^{-1}$. For the folding rate, $E_{\mathrm{a}}$ is $30.04 \pm 1.40 \mathrm{~kJ} \mathrm{~mol}^{-1}$, whereas for the unfolding rate $E_{\mathrm{a}}$ is $84.41 \pm 1.39 \mathrm{~kJ} \mathrm{~mol}^{-1}$. The effect of the different magnitudes of the activation energies becomes obvious in Fig. 7 (right). The temperature-induced descent of the relaxation times is stronger for unfolding $\left(\tau_{\mathrm{u}}\right)$ than for folding $\left(\tau_{\mathrm{f}}\right)$ within the observed temperature range. This difference is reflected by the different activation energy values.

Table 4 shows a comparison of the folding $\left(\tau_{\mathrm{f}}\right)$ and unfolding $\left(\tau_{\mathrm{u}}\right)$ times at selected temperatures. At low temperatures $(285 \mathrm{~K})$, the unfolding process is much slower $\left(\tau_{\mathrm{u}} \sim 23.95 \mu \mathrm{s}\right)$ than the folding process $\left(\tau_{\mathrm{f}} \sim\right.$ $4.57 \mu \mathrm{s})$. At the transition temperature $(307 \mathrm{~K})$, the folding and unfolding times are identical $\left(\tau_{\mathrm{u}}=\tau_{\mathrm{f}}=1.84 \mu \mathrm{s}\right)$. At higher temperatures $(320 \mathrm{~K})$, the folding time $\left(\tau_{\mathrm{f}} \sim\right.$ $1.14 \mu \mathrm{s})$ is slower than the unfolding time $\left(\tau_{\mathrm{u}} \sim 0.49 \mu \mathrm{s}\right)$. This behavior is also illustrated in Fig. 7.

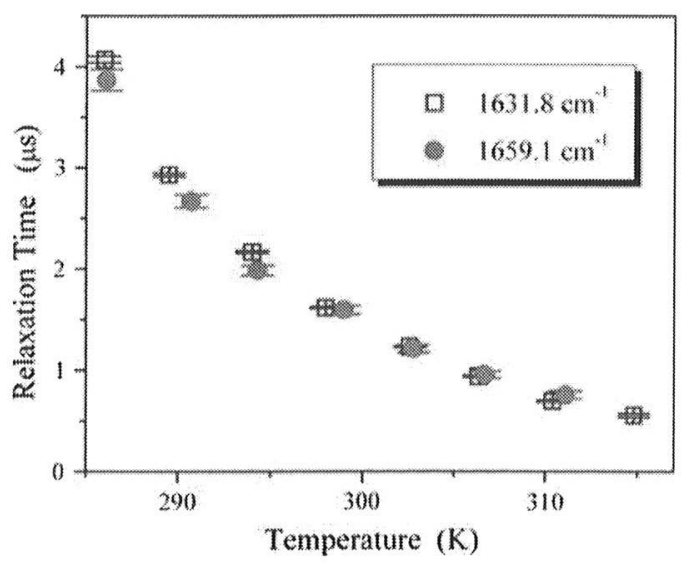

Fig. 6 Relaxation times of polyglutamic acid versus peptide temper atures after the $\mathrm{T}$ jump. The relaxation times decrease with increasing temperature and match for $1,631.8 \mathrm{~cm}^{-1}$ (squares) and $1,659.1 \mathrm{~cm}^{-1}$ (filled circles), indicating a two state process 
Table 2 Temperature dependent relaxation times of polyglutamic acid (pD 5.4) observed at different wavenumbers
Temperatures refer to the peptide temperatures after the $\mathrm{T}$ jump

\begin{tabular}{lllll}
\hline $1,631.8 \mathrm{~cm}^{-1}$ & & & $1,659.1 \mathrm{~cm}^{-1}$ \\
Temperature $(K)$ & Relaxation time $(\mu \mathrm{s})$ & & Temperature $(K)$ & Relaxation time $(\mu \mathrm{s})$ \\
\hline 286.0 & $4.07 \pm 0.03$ & & 286.1 & $3.87 \pm 0.11$ \\
289.5 & $2.93 \pm 0.02$ & & 290.7 & $2.67 \pm 0.06$ \\
294.0 & $2.17 \pm 0.01$ & & 294.3 & $1.99 \pm 0.05$ \\
298.0 & $1.62 \pm 0.01$ & & 299.0 & $1.60 \pm 0.04$ \\
302.6 & $1.23 \pm 0.01$ & & 302.8 & $1.21 \pm 0.04$ \\
306.4 & $0.94 \pm 0.01$ & & 306.7 & $0.96 \pm 0.04$ \\
310.4 & $0.70 \pm 0.01$ & 311.1 & $0.76 \pm 0.04$ \\
314.8 & $0.56 \pm 0.01$ & & \\
\hline
\end{tabular}

Fig. 7 Analysis of the temperature dependent relaxation times of polyglutamic acid. Left Arrhenius plot of the observed relaxation rates $k_{\mathrm{ob}}$ (squares) and the evaluated folding $k_{\mathrm{f}}$ (inverted triangles) and unfolding $k_{\mathrm{u}}$ (filled circles) rates. Right Corresponding relaxation times. Fits were derived using the Arrhenius equation $\ln (k) \quad \ln (A) \quad E_{\mathrm{a}} / R T$
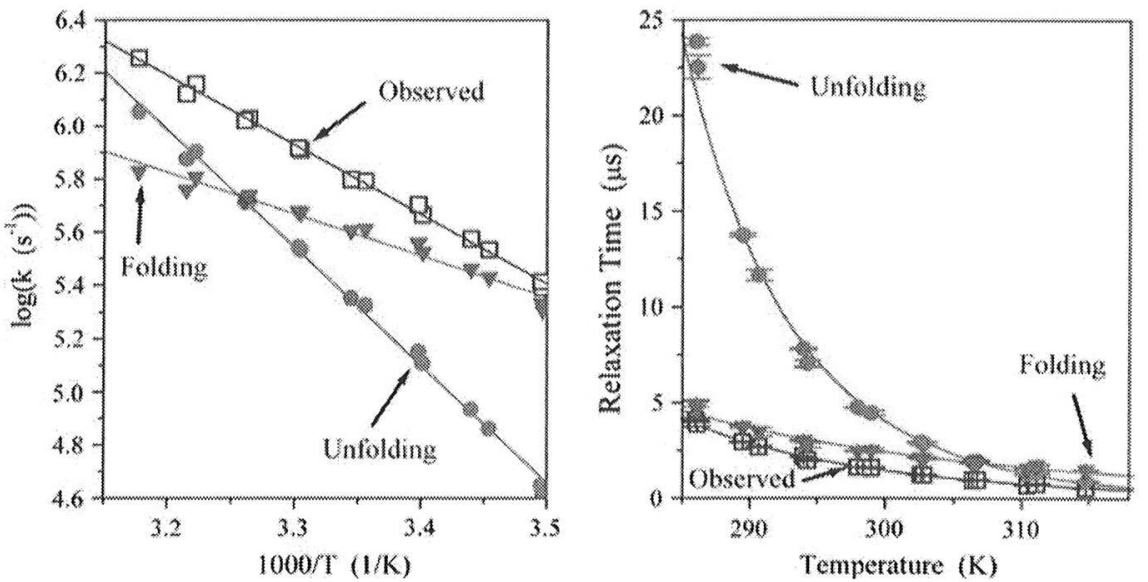

Table 3 Activation energies of polyglutamic acid (pD 5.4) deter mined with the Arrhenius equation $\ln (k) \quad \ln (A) \quad E_{\mathrm{a}} / R T$

\begin{tabular}{lll}
\hline & $E_{\mathrm{a}}\left(\mathrm{kJ} \mathrm{mol}^{-1}\right)$ & $\ln (A)$ \\
\hline$k_{\text {obs }}$ & $50.00 \pm 0.84$ & $33.50 \pm 0.34$ \\
$k_{\mathrm{f}}$ & $30.04 \pm 1.40$ & $24.98 \pm 0.56$ \\
$k_{\mathrm{u}}$ & $84.41 \pm 1.39$ & $46.26 \pm 0.56$ \\
\hline
\end{tabular}

\section{Discussion}

Conformation of polyglutamic acid at different $\mathrm{pD}$ values

It is commonly known that the conformational state of polyglutamic acid is dominated by the extent of ionization of its side-chains (Lumry et al. 1964; Itoh et al. 1976). Thus, variations of $\mathrm{pH}$ induce conformational transitions (Brodi et al. 1999). At pD 4.4, the position of the amide $\mathrm{I}^{\prime}$ band at $1,640 \mathrm{~cm}^{-1}$ indicates $\alpha$-helical structure at low temperatures $(<303 \mathrm{~K})$ (Fig. 1). The intensity decrease of the amide $\mathrm{I}^{\prime}$ band upon heating arises from the loss of the $\alpha$-helical structure. The structural transition is characterized by the transition temperature $T_{\mathrm{m}}$ of $307 \mathrm{~K}$. Along with
Table 4 Temperature dependence of the folding and unfolding time constants of polyglutamic acid (pD 5.4)

\begin{tabular}{lllr}
\hline$T(K)$ & $\tau_{\text {obs }}(\mu \mathrm{s})$ & $\tau_{\mathrm{f}}(\mu \mathrm{s})$ & $\tau_{\mathrm{u}}(\mu \mathrm{s})$ \\
\hline 285 & 4.14 & 4.57 & 23.95 \\
290 & 2.86 & 3.65 & 12.80 \\
300 & 1.44 & 2.42 & 4.03 \\
307 & 0.91 & 1.84 & 1.84 \\
310 & 0.76 & 1.64 & 1.35 \\
320 & 0.41 & 1.14 & 0.49 \\
\hline
\end{tabular}

Temperatures refer to the peptide temperatures after the $\mathrm{T}$ jump

this structural transition, an increase in absorption is observed at 1,602 and $1,731 \mathrm{~cm}^{-1}$. These bands remain after recooling of the sample. This irreversible process gives clear hints for an aggregation process, although the observed frequencies are unusually low $\left(1,602 \mathrm{~cm}^{-1}\right)$ and high $\left(1,731 \mathrm{~cm}^{-1}\right)$ for IR aggregation bands.

Also Itoh et al. (1976) determined absorption bands at $\sim 1,732$ and $\sim 1,599 \mathrm{~cm}^{-1}$ for polyglutamic acid when studying the thermal stability of polyglutamic acid in $\mathrm{D}_{2} \mathrm{O}$ suspensions and thin films. First, typical IR aggregation bands were observed at 1,616 and $1,681 \mathrm{~cm}^{-1}$, and the 
peptide conformation was assigned to a $\beta_{1}$-structure. Further heating for up to $90 \mathrm{~h}$ revealed an increase of absorption intensity at $\sim 1,732$ and $\sim 1,599 \mathrm{~cm}^{-1}$. Simultaneously, the absorption intensities at 1,616 and $1,681 \mathrm{~cm}^{-1}$ were reduced. It was assumed that there are two different existing structures of aggregation states for polyglutamic acid, $\beta_{1}$ and $\beta_{2}$, which was also confirmed by additional $\mathrm{X}$-ray diffraction experiments. The $\beta_{2}$-structure is assumed to be a very tightly packed antiparallel $\beta$-sheet structure, even more compact than the normal $\beta$-sheet structure.

In contrast to Itoh et al. we used polyglutamic acid dissolved in $\mathrm{D}_{2} \mathrm{O}$ solution. Our FTIR studies indicated a conformational change from the $\alpha$-helical structure at low temperature $(<303 \mathrm{~K})$ directly to the conformation assigned as $\beta_{2}$-structure at high temperature $(>323 \mathrm{~K})$ based on the suggestions made by Itoh et al. previously. CD experiments confirmed the loss of $\alpha$-helix content and the onset of aggregated $\beta$-sheets upon heating as the single minimum at $208 \mathrm{~nm}$ appears in the CD spectra. Thus, it turned out that the combination of both techniques is necessary to assign spectral changes to the helix aggregation process.

At pD 4.8, the thermal stability changes slightly. In comparison with $\mathrm{pD} 4.4$, we could show that the structural transition of the $\alpha$-helix occurs over a broader temperature range at $\mathrm{pD}$ 4.8. Furthermore, the IR absorption bands of the aggregated $\beta_{2}$-conformation at $\sim 1,599$ and $\sim 1,730 \mathrm{~cm}^{-1}$ are not as intense as at $\mathrm{pD} 4.4$. We assume that this spectral property is influenced by the increased extent of ionized carboxyl chains $\mathrm{COO}^{-}$, observable by the increase of the absorption band at $\sim 1,565 \mathrm{~cm}^{-1}$. These ionized side-chains seem to destabilize the $\beta_{2}$-conformation of the aggregated structure.

At pD 5.4, an $\alpha$-helical conformation is still present at low temperatures $(\sim 278 \mathrm{~K})$. The $\alpha$-helix band at $1,638 \mathrm{~cm}^{-1}$ diminishes continuously upon heating. The structural transition is completed at temperatures above $323 \mathrm{~K}$. The band at $1,650 \mathrm{~cm}^{-1}$ indicates a coil conformation. The spectral data of both techniques, FTIR and $\mathrm{CD}$, confirm the temperature-induced structural change from an $\alpha$-helix to a coil conformation. Besides the helix

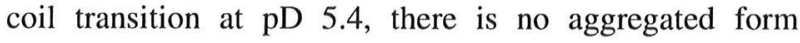
observable. The ionized carboxyl chains $\mathrm{COO}^{-}$cause a stabilizing effect on the peptide conformation and prevent aggregation. A reversible un- and refolding process is observable and can be repeated several times. This reversibility is essential to probe the structural dynamics with T-jump measurements.

At pD 6.2, polyglutamic acid has no $\alpha$-helical contributions, as can be seen in the CD spectra. The frequency shift of the amide $\mathrm{I}^{\prime}$ band to $1,645 \mathrm{~cm}^{-1}$ indicates a random coil structure. Both spectroscopic techniques confirm the loss of the $\alpha$-helix conformation. Temperature variations induce only slight conformational changes at this $\mathrm{pD}$.

Summarizing the data determined in thermal equilibrium, the different effects of the temperature-induced structural changes of polyglutamic acid depend primarily on the extent of ionized side-chains. At concentration of $20 \mathrm{mg} / \mathrm{ml}$, irreversible aggregation processes are induced upon heating at pD 4.4 and 4.8 , while a reversible helix coil transition is observed at $\mathrm{pD} 5.4$. At $\mathrm{pD} 6.2$, the peptide has lost its $\alpha$-helical structure.

Our analysis of the equilibrium as well as the timeresolved data is based on a two-state model. Evaluating equilibrium data, the application of such a model is usually justified by the existence of an isosbestic point. The structural transition is then probed with the simplified assumption that both the folded and unfolded state can be represented by an absorption band usually described with a Gaussian profile. The Gaussian band profile contains three parameters: width, frequency, and area. A spectral transition is observed if one band decreases in intensity while the other band increases. An isosbestic point appears if both bands overlap and only the band areas vary, caused by the extent of the folded and unfolded states. However, there is no exact isosbestic point observable if simultaneously any changes in band frequency or width occur, as we saw with artificially generated spectra. Nevertheless, the lack of an isosbestic point does not exclude the assumption of a twostate model of the folding process. As shown in Fig. 3, there is no accurate isosbestic point observable in our measured spectra, but rather an isosbestic point that is extended over a few wavenumbers. However, we performed our structural analysis of the equilibrium data based on a two-state model (Eqs. 14 ). The T-jump kinetics of the peptide were described by a mono-exponential decay function, and the evaluation of the relaxation time constants was well suited to the equilibrium data. The analysis approaches used indicate that the assumption of a two-state folding model for the helix coil transition of polyglutamic acid is justified. Other T-jump studies of $\alpha$-helical alaninebased peptides used a similar analysis approach based on a two-state model (Williams et al. 1996; Lednev et al. 1999).

The relaxation times determined in this study (Table 2) are comparable to values of other groups that used different techniques but similar temperature and $\mathrm{pH}$ conditions. Tsuji et al. (1976) studied the relaxation of polyglutamic acid using an electric field pulse method, detecting the change of conductivity. Relaxation rates of the polymer in $\mathrm{H}_{2} \mathrm{O}$ solution of $\sim 3.3 \mu$ s at $\mathrm{pH} 6.5$ and $\sim 288 \mathrm{~K}$ were determined. Also, Yasunaga et al. (1973) used this technique to induce and detect conformational changes of polyglutamic acid dissolved in $\mathrm{H}_{2} \mathrm{O}$. At $\mathrm{pH}$ 5.6, a time constant of $\sim 2.9 \mu$ s at $293 \mathrm{~K}$ was found for the probed helix coil transition. Cummings and Eyring (1975) 
reported results of the helix coil transition of polyglutamic acid using an optical rotation electric field-jump technique. Relaxation times of $1.7 \mu$ s were determined at $\mathrm{pH} 5.9$ and 297 K. The group of Barksdale and Stuehr (1972) performed ultrasonic absorption measurement to observe relaxation dynamics of polyglutamic acid. The relaxation time was $1.0 \mu \mathrm{s}$ at $\mathrm{pH} 5.2$ and $310 \mathrm{~K}$. Also, T-jump results of polyglutamic acid were reported by Nolan et al. (2005). They determined relaxation times at $1,632 \mathrm{~cm}^{-1}$ as a function of the helicity, which was adjusted by changing the $\mathrm{pD}$. The time constants varied between 0.9 and $1.8 \mu \mathrm{s}$ at room temperature.

In our study, we determined relaxation time constants for polyglutamic acid in $\mathrm{D}_{2} \mathrm{O}$ solution. At $\mathrm{pD} 5.4$, the temperature-dependent time constants of the $\alpha$-helix decay probed at 1,632 $\mathrm{cm}^{-1}$ varied between $\sim 0.5$ and $\sim 4.1 \mu \mathrm{s}$ over a temperature range of $\sim 276$ to $\sim 304 \mathrm{~K}$. Thus, our time constants agree with the results of other studies described above. Furthermore, we observed that the relaxation times probed at $1,631.8$ and $1,659.1 \mathrm{~cm}^{-1}$ are nearly identical for various temperatures. The analysis of the data using a two-state model seems to be justified, at least within our probed time range of $500 \mathrm{~ns}$ to $200 \mu \mathrm{s}$. There are processes that occur on faster time scales (Yasunaga et al. 1973; Tsuji et al. 1976; Sano and Yasunaga 1980) and that may possibly initiate the helix coil transition by a nucleation process. We decomposed our observed relaxation times in un- and refolding by using the equilibrium constant $K_{\mathrm{eq}}(T)$ determined from static absorption measurements. Table 4 gives the temperature dependence of the folding and unfolding time constants at selected temperatures. At temperatures below the transition temperature of $307 \mathrm{~K}$, the relaxation process is dominated by the rapid folding of the peptide and a slower unfolding dynamics. The $\alpha$-helix structure is more favorable in this temperature range, and the folding time constant is faster than the unfolding time constant. Above $307 \mathrm{~K}$, the coil conformation is energetically more favorable, as observed in a faster unfolding time constant.

Kimura et al. reported different relaxation rates for the helix coil transition by using time-resolved FTIR and CD experiments (Kimura et al. 2002). They induced $\mathrm{pH}$ jumps by a rapid mixing method and studied polyglutamic acid with different polymeric sizes. With a fast $\mathrm{pD}$ change from 8.0 to 4.9 , relaxation rates of $4,000 \pm 600 \mathrm{~s}^{-1}$ corresponding to relaxation time constants of $250 \pm 38 \mu$ s were reported. This relaxation was probed within a time range of $50 \mu \mathrm{s}$ to $\sim 1 \mathrm{~ms}$. Kimura et al. suggested that polyglutamic acid forms intramolecular hydrogen bonds which probably trap the peptide into a kink conformation and block the propagation of the helices until $100 \mu \mathrm{s}$. They concluded that the helix formation process of polyglutamic acid involves more than one kinetic step, such as the formation of short helices and their elongation. We determined relaxation time constants for the helix coil transition of $\sim 4.1 \mu$ s at $286 \mathrm{~K}$, evaluating a time interval of $500 \mathrm{~ns}$ to $200 \mu$ s. A reason for the different observations made by Kimura et al. previously and by us herein lies certainly in the different measuring conditions, as we induce a T-jump for initiation of the helix coil transition without changing the extent of side-chain ionization, whereas Kimura et al. induce a $\mathrm{pD}$ change that results in a coil helix transition accompanied by a changed fraction of ionized side-chains, which will impact on the dynamics of the transition. Another difference is the larger polymer length we used. A larger peptide size usually leads to slower dynamics. Thus, the time constant that we determined might be an early step of a multistate transition with additional slower components which are not detectable within the time interval probed by our measurements.

\section{Conclusions}

We studied the thermal stability and folding dynamics of polyglutamic acid at various $\mathrm{pD}$ values. The combination of static FTIR and CD measurements in thermal equilibrium characterized the conformation as a function of $\mathrm{pD}$. At $\mathrm{pD}$ values below 5.4, a transition from a helix conformation to an aggregated structure was monitored upon heating. At pD 5.4, a reversible helix coil transition was observed, and above pD 6.2, polyglutamic acid forms a coil conformation which is quite temperature stable. Thus, both the $\mathrm{pD}$ and the extent of ionization of the sidechains are crucial for the peptide conformation and its thermal stability. In addition, we performed time-resolved T-jump experiments at single wavelengths to probe the conformational dynamics. At pD 5.4, the dynamics of the helix coil transition was studied in the amide $\mathrm{I}^{\prime}$ region at $1,631.8$ and $1,659.1 \mathrm{~cm}^{-1}$. These selected wavelengths represent the decay of $\alpha$-helix and the increase of coil structure upon heating. It was shown that the relaxation rates only depend on temperature but not on the wavelength probed. This supports the assumption of a two-state model for the kinetic analysis of the helix coil transition that we evaluated in a time interval from $500 \mathrm{~ns}$ to $200 \mu \mathrm{s}$. By combining static and time-resolved experiments, we decomposed folding and unfolding for various peptide temperatures. At the transition temperature $T_{\mathrm{m}}$, the relaxation time constants are identical for folding and unfolding. Below $T_{\mathrm{m}}$, time constants for folding are faster than for unfolding, whereas the opposite applies above $T_{\mathrm{m}}$. The different temperature dependences of folding and unfolding were supported by the derived activation energies. 
Acknowledgments This work was supported by the Ministry of Science and Culture of Hesse (HMWK) and by the University of Frankfurt (Förderfond koordinierter Programme).

\section{References}

Abbruzzetti S, Viappiani C, Small JR, Libertini LJ, Small EW (2000) Kinetics of local helix formation in poly $\mathrm{L}$ glutamic acid studied by time resolved photoacoustics: neutralization reactions of carboxylates in aqueous solutions and their relevance to the problem of protein folding. Biophys J 79:2714 2721

Allen DL, Pielak GJ (1998) Baseline length and automated fitting of denaturation data. Protein Sci 7:1262 1263

Anfinrud PA, Han C, Hochstrasser RM (1989) Direct observation of ligand dynamics in hemoglobin by subpicosecond infrared spectroscopy. Proc Natl Acad Sci 86:8387 8391

Ballew RM, Sabelko J, Reiner C, Gruebele M (1996) A single sweep, nanosecond time resolution laser temperature jump apparatus. Rev Sci Instrum 67:3694 3699

Barksdale AD, Stuehr JE (1972) Kinetics of the helix coil transition in aqueous poly( $\mathrm{L}$ glutamic acid). J Am Chem Soc 94:3334 3338

Barth A, Zscherp C (2002) What vibrations tell us about proteins. Q Rev Biophys 35:369 430

Bieri O, Kiefhaber T (2000) Kinetic models in protein folding. In: Pain RH (ed) Protein folding: frontiers in molecular biology. Oxford University Press, Oxford, pp 3464

Brodi F, Cametti C, Paradossi G (1999) Side chain dynamics in $\operatorname{poly}(\alpha$ glutamate $)$ and $\operatorname{poly}(\gamma$ glutamate $)$ aqueous solutions: a high frequency dielectric investigation. Phys Chem Chem Phys 1:1555 1561

Byler DM, Susi H (1986) Examination of the secondary structure of proteins by deconvolved FTIR spectra. Biopolymers 25:469 487

Chirgadze YN, Brazhnikov EV (1974) Intensities and other spectral parameters of infrared amide bands of polypeptides in the $\alpha$ helical form. Biopolymers 13:1701 1712

Chirgadze YN, Brazhnikov EV, Nevskaya NA (1976) Intramolecular distortion of the $\alpha$ helical structure of polypeptides. J Mol Biol 102:781 792

Clarke DT, Doig AJ, Stapley BJ, Jones GR (1999) The $\alpha$ helix folds on the millisecond time scale. Proc Natl Acad Sci 96:7232 7237

Covington AK (1968) Use of the glass electrode in deuterium oxide and the relation between the standardized $\mathrm{pD}\left(\mathrm{pa}_{\mathrm{D}}\right)$ scale and the operational $\mathrm{pH}$ in heavy water. Anal Chem 40:700 706

Cummings AL, Eyring EM (1975) Helix coil transition kinetics in aqueous poly( $\alpha$, L glutamic Acid). Biopolymers 14:2107 2114

Dimitriadis G, Drysdale A, Myers J, Arora P, Radford SE, Oas TG, Smith DA (2004) Microsecond folding dynamics of the F13W G29A mutant of the B domain of staphylococcal protein A by laser induced temperature jump. Proc Natl Acad Sci 101:3809 3814

Dyer RB, Maness SJ, Peterson ES, Franzen S, Fesinmeyer RM, Andersen NH (2004) The mechanism of $\beta$ hairpin formation. Biochemistry 43:11560 11566

Genberg L, Heisel F, McLendon G, Dwayne Miller RJ (1987) Vibrational energy relaxation processes in heme proteins: model systems of vibrational energy dispersion in disordered systems. J Phys Chem 91:5521 5524

Gooding EA, Ramajo AP, Wang J, Palmer C, Fouts E, Volk M (2005) The effects of individual amino acids on the fast folding dynamics of $\alpha$ helical peptides. Chem Commun 48:5985 5987

Hauser K, Krejtschi C, Huang R, Wu L, Keiderling TA (2008) Site specific relaxation kinetics of a tryptophan zipper hairpin peptide using temperature jump IR spectroscopy and isotopic labeling. J Am Chem Soc 130:2984 2992

Huang C Y, Klemke JW, Getahun Z, DeGrado WF, Gai F (2001) Temperature dependent helix coil transition of an alanine based peptide. J Am Chem Soc 123:92359238

Itoh K, Foxman BM, Fasman GD (1976) The two $\beta$ forms of poly (L glutamic Acid). Biopolymers 15:419 455

John DM, Weeks KM (2000) Van't Hoff enthalpies without baselines. Protein Sci 9:1416 1419

Kimura T, Takahashi S, Akiyama S, Uzawa T, Ishimori K, Morishima I (2002) Direct observation of the multistep helix formation of poly L glutamic acids. J Am Chem Soc 124:11596 11597

Krejtschi C, Huang R, Keiderling TA, Hauser K (2008) Time resolved temperature jump infrared spectroscopy of peptides with well defined secondary structure: a Trpzip $\beta$ hairpin variant as an example. Vib Spectrosc 48:1 7

Lednev IK, Karnoup AS, Sparrow MC, Asher SA (1999) $\alpha$ helix peptide folding and unfolding activation barriers: a nanosecond UV resonance Raman study. J Am Chem Soc 121:8074 8086

Lumry R, Legare R, Miller WG (1964) The dynamics of the helix coil transition in poly $\alpha$, L glutamic Acid. Biopolymers 2:489 500

Myer YP (1969) The $\mathrm{pH}$ induced helix coil transition of poly $\mathrm{L}$ lysine and poly L glutamic acid and the $238 \mu \mathrm{m}$ dichroic band Macromolecules 2:624 628

Nolan B, Gooding E, Sharma S, Volk M (2005) The helix coil transition in polyglumatic acid. Biophys $\mathrm{J}$ 88:34A

Petty SA, Volk M (2004) Fast folding dynamics of an $\alpha$ helical peptide with bulky side chains. Phys Chem Chem Phys 6:1022 1030

Ramajo AP, Petty SA, Volk M (2006) Fast folding dynamics of $\alpha$ helical peptides effect of solvent additives and $\mathrm{pH}$. Chem Phys 323:11 23

Rucker AL, Pager CT, Campbell MN, Qualls JE, Creamer TP (2003) Host guest scale of left handed polyproline II helix formation. Proteins 53:68 75

Sano T, Yasunaga T (1980) Kinetics of helix coil transition of polypeptides in solution by the relaxation methods. Biophys Chem 11:377 386

Schwarz G, Seelig J (1968) Kinetic properties of the electric field effect of the helix coil transition of poly( $\gamma$ benzyl L glutamate) determined from dielectric relaxation measurements. Biopoly mers 6:1263 1277

Snipp RL, Miller WG, Nylund RE (1965) The charge induced helix random coil transition in aqueous solution. J Am Chem Soc $87: 35473553$

Takano K, Saito M, Morikawa M, Kanaya S (2004) Mutational and structural based analyses of the osmolyte effect on protein stability. J Biochem 135:701 708

Tsuji Y, Yasunaga T, Sano T, Ushio H (1976) Kinetic studies of the helix coil transition in aqueous solutions of poly $(\alpha \mathrm{L}$ glutamic acid) using the electric field pulse method. J Am Chem Soc 98:813 818

van Stokkum IHM, Linsdell H, Hadden JM, Haris PI, Chapman D, Bloemendal M (1995) Temperature induced changes in protein structures studied by Fourier transform infrared spectroscopy and global analysis. Biochemistry 34:10508 10518

Venyaminov SY, Kalnin NN (1990) Quantitative IR spectrophotom etry of peptide compounds in water $\left(\mathrm{H}_{2} \mathrm{O}\right)$ solutions II. Amide absorption bands of polypeptides in fibrous proteins in $\alpha, \beta$, and random coil conformations. Biopolymers 30:1259 1271

Venyaminov S Yu, Prendergast FG (1997) Water $\left(\mathrm{H}_{2} \mathrm{O}\right.$ and $\left.\mathrm{D}_{2} \mathrm{O}\right)$ molar absorptivity in the $10004000 \mathrm{~cm}^{-1}$ range and quantita tive infrared spectroscopy of aqueous solution. Anal Biochem 248:234 245 
Walsh STR, Walsh R, Cheng P, Wright WW, Daggett V, Vanderkooi JM, Degrado WF (2003) The hydration of amides in helices: a comprehensive picture from molecular dynamics, IR and NMR. Protein Sci 12:520 531

Williams S, Causgrove TP, Gilmanshin R, Fang KS, Callender RH, Woodruff WH, Dyer RB (1996) Fast events in protein folding: helix melting and formation in a small peptide. Biochemistry 35:691 697

Wray WO, Aida T, Dyer RB (2002) Photoacoustic cavitation and heat transfer effects in the laser induced temperature jump in water. Appl Phys B 74:57 66

Xu Y, Oyola R, Gai F (2003) Infrared study of the stability and folding kinetics of a 15 residue $\beta$ hairpin. J Am Chem Soc 125:15388 15394

Yadav S, Ahmad F (2000) A new method for the determination of stability parameters of proteins from their heat induced dena turation curves. Anal Biochem 283:207 213
Yasunaga T, Sano T, Takahashi K, Takenaka H, Ito S (1973) Helix coil transition of poly $\alpha, \mathrm{L}$ glutamic acid in aqueous solution studied by the dissociation field effect relaxation method. Chem Lett 4:405 408

Yoder G, Pancoska P, Keiderling TA (1997) Characterization of alanine rich peptides, Ac (AAKAA) $n$ GY NH2 ( $\left.\begin{array}{lll}n & 1 & 4\end{array}\right)$, using vibrational circular dichroism and Fourier transform infrared. Conformational determination and thermal unfolding. Biochemistry 36:15123 15133

Zscherp C, Aygün H, Engels JW, Mäntele W (2003) Effect of proline to alanine mutation on the thermal stability of the all $\beta$ sheet protein tendamistat. Biochim Biophys Acta 1651:139 145 